\title{
A pós-graduação no Brasil, a pesquisa em educação e os estudos sobre a política educacional: os contornos da constituição de um campo acadêmico
}

\author{
Ana Lúcia Felix dos Santos \\ Janete Maria Lins de Azevedo \\ Universidade Federal de Pernambuco, Programa de Pós-Graduação em Educação
}

\section{Considerações iniciais}

As políticas públicas para educação vêm sendo foco de pesquisas e estudos sistemáticos, como exemplifica o grande número de programas de pósgraduação em educação que possuem linhas de investigação vinculadas a essa temática e como atestam os estudos do tipo estado da arte. Essa atenção pode ser entendida como fruto das mudanças ocorridas em nossa sociedade que trouxeram as políticas públicas para o centro da cena dos debates sociopolíticos, em particular os voltados para a negação dos direitos sociais e para a premência de seu resgate e usufruto para e pela maioria da população. Trata-se de fenômeno que também vem influenciando a complexidade e a dinâmica dos próprios programas de pós-graduação, ao mesmo tempo em que recebe influências deles.

Partindo da consideração de que os cursos de mestrado e doutorado constituem um lugar privilegiado de produção do conhecimento, dada a centralidade que a pesquisa científica deve neles assumir, este artigo problematiza a questão em foco a partir de uma análise da política para a pós-graduação em educação no Bra- sil. Assim, analisaremos a trajetória da pós-graduação brasileira e a inserção e evolução da pesquisa educacional no interior desse processo. Essa estratégia visa apontar o lugar dos estudos sobre política educacional no seio dos programas de pós-graduação em educação, buscando desvelar a sua emergência e consolidação como objeto de investigação.

Nossas reflexões, com base em construto teórico de Pierre Bourdieu, têm por suposto que a política educacional, como de resto toda política pública, não se constrói num vazio. Como resultado da ação humana, é definida e implementada em estreita articulação com o contexto sociopolítico, econômico e cultural do qual emerge. Portanto, sofre as influências dos embates políticos, dos conflitos e contradições próprios de uma sociedade de classes bem como do universo cultural e simbólico peculiar a nossa realidade, dimensões que se apresentam intimamente articuladas.

\section{A política de pós-graduação no Brasil}

Como sabemos, o sistema de pós-graduação no Brasil possui reconhecimento por parte da comunidade 
científica, nacional e internacional. Tal reconhecimento se deve ao formato e à seriedade que as políticas públicas para a pós-graduação tomaram em termos de definições e das ações voltadas para esse setor, o que se expressou, entre outros modos, em sua expansão contínua, com qualidade, nos últimos 40 anos. Nos anos de 1960, havia 38 cursos instalados no país; em 2008 eram 2.588, conforme pode ser visto no Quadro 1.

Quadro 1: Cursos de mestrado e doutorado reconhecidos pela CAPES, por região geográfica

\begin{tabular}{|l|r|r|r|r|r|r|c|r|r|}
\hline \multirow{3}{*}{ Região } & \multicolumn{4}{|c|}{$\begin{array}{c}\text { Programas e cursos } \\
\text { de pós-graduação }\end{array}$} & \multicolumn{4}{c|}{$\begin{array}{c}\text { Totais de cursos } \\
\text { de pós-graduação }\end{array}$} \\
\cline { 2 - 11 } & Total & $\mathrm{M}$ & $\mathrm{D}$ & $\mathrm{F}$ & $\mathrm{M} / \mathrm{D}$ & Total & $\mathrm{M}$ & $\mathrm{D}$ & $\mathrm{F}$ \\
\hline $\begin{array}{l}\text { Centro- } \\
\text { Oeste }\end{array}$ & 184 & 93 & 2 & 17 & 72 & 256 & 165 & 74 & 17 \\
\hline Nordeste & 456 & 249 & 14 & 37 & 156 & 612 & 405 & 170 & 37 \\
\hline Norte & 110 & 68 & 2 & 6 & 34 & 144 & 102 & 36 & 6 \\
\hline Sudeste & 1.316 & 399 & 18 & 122 & 777 & 2.093 & 1.176 & 795 & 122 \\
\hline Sul & 522 & 242 & 5 & 43 & 232 & 754 & 474 & 237 & 43 \\
\hline Brasil & 2.588 & 1.051 & 41 & 225 & 1.271 & 3.859 & 2.322 & 1.312 & 225 \\
\hline
\end{tabular}

Fonte: MEC/CAPES. Última atualização: 15 de maio de 2008. Legenda: M: mestrado acadêmico; D: doutorado; F: mestrado profissionalizante.

Programas: M/D - Mestrado acadêmico/doutorado.

Mesmo que o Quadro 1 coloque em relevo um dos grandes problemas que ainda assolam o sistema de pós-graduação - a assimetria regional, já que na Região Sudeste se localizam $61,1 \%$ dos programas com mestrado e doutorado -, pode-se identificar um claro avanço quantitativo, que também foi acompanhado de um avanço qualitativo. Segundo Cury (2004), tal sucesso se deve a uma atuação efetiva do Estado brasileiro:

Tal política pública propiciou uma realidade bem-sucedida logo convertida em verdadeiro sistema com um reconhecimento nacional e internacional de sua qualidade. Nesse processo especial destaque se confere aos processos de avaliação levados adiante pela Coordenação de Aperfeiçoamento de Pessoal de Nível Superior (CAPES). Cooperam para tal tanto as bolsas concedidas por esta fundação, pelo CNPq e também por algumas fundações estaduais de amparo à pesquisa (FAPs) quanto outros programas de apoio e fomento fornecidos por tais agências. (Cury, 2004, p. 780)
Severino (2006) concorda com essa afirmação e diz que a pós-graduação tem contribuído valiosamente para o melhor conhecimento dos problemas que emergem de diversos âmbitos da nossa realidade e para a qualificação de expressivo quadro de profissionais nas áreas de ensino, gestão e pesquisa.

\begin{abstract}
Sem nenhuma dúvida, a pós-graduação no País se transformou numa sementeira de pesquisadores, o que contribuiu para a consolidação do quadro de recursos humanos para todos os setores da vida nacional. Pode-se afirmar com segurança que a pós-graduação é um dos melhores segmentos do sistema educacional brasileiro sob o critério do nível de qualidade alcançado e vem contribuindo significativamente para a construção de um retrato mais fiel da realidade nacional, graças à sistematização e à institucionalização da prática científica de investigação, ao mesmo tempo em que forma novas gerações de pesquisadores. (Severino, 2006, p. 51-52)
\end{abstract}

Esse sistema está marcado por rigoroso processo de reconhecimento de programas e de avaliação e alto grau de flexibilidade organizacional, articulada com possibilidades interdisciplinares e financiamento específico. Institucionalmente, nossa pós-graduação data da década de 1960, quando foi aprovado o parecer n. 977, em 3 de dezembro de 1965, pela Câmara de Ensino Superior (CES) do então Conselho Federal de Educação (CFE). Esse documento teve como objetivo esclarecer a natureza e os objetivos desse ramo da educação e, segundo Cury (2005), foi e ainda continua sendo a referência sistemática para a organização e implementação da pós-graduação brasileira.

Vale lembrar que, antes de sua vigência, já havia entre nós cursos de pós-graduação em funcionamento. Na década de 1960, o Brasil contava com 38 cursos, sendo 11 de doutorado e 27 de mestrado (Velloso, 2002). No entanto, não havia uma definição clara dos fins e objetivos da pós-graduação, nem da sua estrutura. Foi esse um dos motivos que levaram à elaboração do referido parecer, tendo em vista a necessidade de implantar e desenvolver no ensino superior a pósgraduação, cuja definição e regulamentação viriam 
superar a "imprecisão que reina[va] entre nós sobre a natureza desses cursos” (Brasil, 1965).

Cunha (1991) lembra que são passíveis de crítica as formas como se deram as transformações do ensino superior e da pós-graduação no Brasil durante o regime militar. As transformações seguiram uma filosofia de ação tecnicista apoiada em um tipo de regulação própria de regimes de exceção, além de se basearem no modelo norte-americano, país que procurava estabelecer controles sobre as sociedades periféricas como era o nosso caso. Entretanto, não se pode negar o grande impulso alcançado por esse nível do sistema educacional após o golpe de 1964. O próprio Estatuto do Magistério Superior, promulgado em 1965, “induzia a demanda de pós-graduação, na medida em que direcionava a ascensão da carreira docente à obtenção de títulos de mestrado e doutorado” (p. 59).

Durante o regime militar, apesar da repressão que mutilou bibliotecas e programas e expulsou professores e alunos do sistema educacional, nenhuma universidade pública foi fechada e houve mais recursos para sua expansão, proporcionando o desenvolvimento das atividades essenciais para sua existência: a produção cultural e a pesquisa científica e tecnológica (Cunha, 1991), ainda que dentro dos limites da repressão e do autoritarismo e voltadas para a formação de elites dirigentes.

É interessante destacar também que o surgimento e a consolidação da pós-graduação no Brasil, assim como do ensino superior de forma geral, foram marcados pela influência externa. Além do modelo norteamericano, também houve influências do modelo francês, tanto na institucionalização da pós-graduação, tal como expressa o conteúdo do parecer n. 977/65, como na constituição/criação autônoma das universidades brasileiras, que se serviram de intelectuais estrangeiros para implantar ou consolidar cursos de graduação e pós-graduação.

O parecer em destaque institucionaliza o modelo norte-americano na pós-graduação que teve sua estrutura organizada em cursos lato sensu (especialização) e stricto sensu (mestrado e doutorado). Os cursos de mestrado e doutorado constituem níveis autônomos entre si, sem relação de pré-requisito entre eles (Brasil, 1965).

No entanto, dada a dinâmica da realidade, aos poucos esse nível de ensino foi tomando contornos particulares às nossas necessidades, na medida em que o sistema foi se tornando mais complexo, mas também na medida em que outras influências se fizeram perceber. A formação de professores e pesquisadores brasileiros no exterior, assim como os acordos de intercâmbio cultural-científico que traziam pesquisadores de vários países para cá, também influenciou a constituição e o padrão assumido pela nossa pós-graduação.

Não obstante, os sucessivos documentos de planejamento formulados e divulgados a partir da década de 1970 demonstram as intenções dos governos no sentido de impulsionar a pós-graduação.

\section{Os planos nacionais de pós-graduação como documentos norteadores da política em questão}

A institucionalização da pós-graduação no Brasil pela via legal, como era de se esperar, não foi suficiente para atingir os objetivos traçados naquele momento: formação qualificada de professores para atender à expansão do ensino superior, elevando seu nível de qualidade, estímulo ao desenvolvimento da pesquisa científica por meio da preparação adequada de pesquisadores e formação de técnicos e intelectuais de alto nível para fazer face às necessidades do desenvolvimento nacional em todos os setores (Brasil, 1965).

Eram necessárias outras medidas articuladas que resultassem na concretização das ações objetivas para instauração e expansão organizada da pós-graduação, de forma inclusive a dar conta das diferentes demandas regionais. Cabe relembrar que nas décadas de 1960/1970 nossa sociedade estava vivendo sob uma ditadura militar, o que se expressava, dentre outras maneiras, em um padrão de regulação social emanado de um Estado burocrático-autoritário (O’Donnell, 1982).

Tratava-se de viabilizar um determinado projeto de sociedade, voltado para a consolidação do capitalismo, por meio de um modelo desenvolvimentista 
que aprofundava a internacionalização do mercado interno e que agudizou nossa situação de dependência. O desenvolvimento e a afirmação da pós-graduação se deram sobretudo no contexto do referido projeto, cuja filosofia de ação, no que respeita à política educacional, se baseava em pressupostos da teoria do capital humano. A formação de recursos humanos de alto nível era vista como necessária para o desenvolvimento, considerando sua essencialidade para o sucesso do projeto de modernização em curso. Essa formação, no entanto, deveria estar diretamente articulada às necessidades do mercado e, portanto, dos setores produtivos (Azevedo, 2004).

No início da década de 1970, a partir da constatação de que o processo de expansão da pós-graduação havia sido até então parcialmente espontâneo, pressionado por motivos conjunturais e pela expansão do ensino superior, os sucessivos governos militares foram estabelecendo medidas para procurar garantir o seu desenvolvimento sistemático. Em 1970 foi instituído o Programa Intensivo de Pós-Graduação (decreto n. 67.348); em 1973, criado um grupo de trabalho com a tarefa de propor medidas iniciais para a definição da política de pós-graduação; em 1974, instituído o Conselho Nacional de Pós-Graduação, ${ }^{1}$ órgão colegiado interministerial cujas funções giravam em torno da formulação da política de pós-graduação e sua execução; e formulado o I Plano Nacional de Pós-Graduação (PNGP) para o período de 1975-1977 (Ferreira, 1999). Em articulação com essas estratégias, foram reforçados organismos governamentais diretamente ligados a esse nível de ensino que viabilizaram, de modo direto ou indireto, os significativos investimentos financeiros necessários ao seu desenvolvimento (Martins, 1991).

De qualquer forma, ao comparar a expansão da graduação e da pós-graduação nacional, no que concerne à pertença administrativa, constatamos que a segunda se expandiu e consolidou em poucas décadas, firmando-se sobretudo no espaço das universidades públicas, ao passo que a primeira teve

${ }^{1}$ Instituído no Ministério da Educação e Cultura (MEC) pelo governo federal pelo decreto n. 73.411, de 4 de janeiro de 1974. sua expansão exposta ao sabor das conjunturas, sem o suporte de uma política educacional sistemática (Brasil, 2004, p. 26). Trata-se de fenômeno que acabou por se expressar em um maior quantitativo de atendimento do ensino superior no Brasil por parte da iniciativa privada.

O I PNPG (1975-1979) apresentou o “conjunto de atividades desenvolvidas nas instituições de ensino superior e nas instituições de pesquisa em nível de pós-graduação”. Apresentou, também, um conjunto de análises e estratégias que deveriam servir como referências "para medidas tomadas em todos os níveis institucionais de coordenação, planejamento, execução e normalização das atividades de pós-graduação durante 5 anos, a partir de 1975” (Brasil, 1975, p. 12).

Esse plano retomou as funções gerais da pósgraduação formar professores para o magistério universitário, a fim de atender à expansão do ensino superior em quantidade e qualidade; formar pesquisadores para maior incremento do trabalho científico e preparar profissionais de nível elevado, em função da demanda de mercado de trabalho nas instituições privadas e públicas. Tudo isso considerando que o sistema de pós-graduação, exercendo adequadamente suas funções, conseguiria chegar ao objetivo fundamental de transformar as universidades em verdadeiros centros de atividades criativas permanentes. Os destaques principais da política de pós-graduação nesse documento eram a capacitação dos docentes das universidades e a integração da pós-graduação ao sistema universitário, além da preocupação com as ciências básicas e com as disparidades regionais, que deveriam ser evitadas (Brasil, 1975, p. 16-17).

O II PNPG (1982-1985) foi formulado e começou a ser implementado nos últimos anos do regime autoritário. A crise econômica que se abateu sobre nosso país naquele momento colaborou para o ocaso do regime militar, que viu suas bases enfraquecidas pelo esgotamento do modelo econômico implantado. Em consequência, houve escassez de recursos para as políticas educacionais, de forma que as prioridades estabelecidas para a pós-graduação foram a racionalização dos investimentos e o reforço de mecanismos 
de acompanhamento e avaliação dos programas, com vistas à melhoria de sua qualidade (Brasil, 1982).

O II PNPG continuava expressando preocupação com os desníveis entre regiões e instituições, decorrentes da heterogeneidade da realidade brasileira. É interessante notar que, em período de recursos escassos, o plano tenha dado ênfase à qualidade do ensino superior e da pós-graduação. Além do que, buscou adequar este último às necessidades do país em termos de produção de ciência e tecnologia, reafirmando, de modo bastante evidente, "sua vinculação com o setor produtivo” (Ramalho \& Madeira, 2005, p. 73).

A recessão dos anos de 1980-1984 veio aprofundar uma crise na universidade que perpassou toda a década de 1980, configurada principalmente pelas limitações de recursos para a pós-graduação. Mas a década também foi caracterizada pela retomada do regime democrático. Nesse contexto, ainda que os recursos tivessem se tornado escassos, observou-se a abertura das decisões e da participação para grupos específicos da sociedade civil, vinculados de algum modo aos estudos pós-graduados e ao setor de ciência e tecnologia. Ao tratar da questão da qualidade então buscada, Ferreira alude indiretamente a essa abertura:

O III Plano Nacional de Pós-Graduação (1986-1989) foi formulado tomando como premissa básica a constatação de que os objetivos centrais do I e do II PNPG, isto é, a consolidação e o fortalecimento qualitativo, não foram plenamente alcançados. Daí que estabeleceu como objetivo geral a transformação dos cursos de pós-graduação em autênticos centros de pesquisa e de formação de docentes/pesquisadores. Para isso, reconheceu a necessidade de estabelecer mecanismos que assegurassem a efetiva participação da comunidade científica na composição dos comitês e órgãos de decisão das agências de fomento da pesquisa e na definição de diretrizes de distribuição de recursos. (Ferreira, 1999, p. 95)

Ainda que a vigência desse terceiro plano coincida com o primeiro governo civil, chamado Nova República, ao qual coube a herança dos perversos resultados socioeconômicos do modelo de desenvolvimento adotado durante a ditadura militar (Azevedo,
2004), os objetivos e as funções nele apresentados não sofreram grandes variações em relação aos anteriores. As mudanças visíveis foram as propostas de cunho democratizante para a sua operacionalização, bastante significativas, em contraposição às práticas autoritárias. Não obstante, o plano buscou priorizar a necessidade de estreitamento das relações entre a universidade, a pós-graduação e o setor produtivo, tanto como meio de buscar novas fontes de financiamento quanto como mecanismo de aplicação das pesquisas e da busca de desenvolvimento de estudos aplicados (Brasil, 1986).

Após esse período existiu ainda um quarto plano, que tramitou nas discussões nacionais mas não foi formalizado, o que não significa ausência de políticas públicas para o setor. "Embora não houvesse formalmente, nos anos de 1990, um IV PNPG, houve um conjunto de medidas que constituíram uma política para a pós-graduação” (Ramalho \& Madeira, 2005, p. 74).

Na prática, os debates em torno da formulação do IV PNPG sugeriram que o mesmo contemplasse dois princípios básicos: autonomia institucional e flexibilização. Isso significava que cada universidade deveria assumir a responsabilidade pela gestão de seu sistema de pós-graduação e propor modelos abertos de acordo com seus objetivos e sua vocação específica. São propostas que se adequavam ao direcionamento imprimido às políticas públicas pelos dois governos de Fernando Henrique Cardoso. Tratava-se das tentativas de diminuição das responsabilidades da União com as políticas, particularmente com as políticas sociais, como era o caso das políticas para a educação.

Ramalho e Madeira (2005) registram que paradoxalmente, num período em que não houve um plano oficial, houve um salto qualitativo e quantitativo na pós-graduação no Nordeste e no Norte. Azevedo (2004) também analisa o período em tela e destaca a restrição no número de bolsas de estudo, nos programas de apoio e fortalecimento dos cursos e nos projetos de qualificação dos docentes do ensino superior. Destaca ainda o acionamento de controles para a expansão dos programas, manifesto no estabelecimento 
de novos critérios para implantação de cursos, como também no sistema de avaliação.

Atualmente estamos vivendo o período do V PNPG (2005-2010), aprovado em janeiro de 2005, que reafirma o princípio de que o sistema educacional é fator estratégico no processo de desenvolvimento socioeconômico e cultural da sociedade brasileira. No que diz respeito ao período de duração, esse plano se diferencia dos anteriores, pois sua vigência está proposta para um período de cinco anos. Na perspectiva de uma política de ação podemos dizer que esse é um dado interessante, já que uma proposta de ação de maior duração é o "mínimo que se exige para o delineamento, para implementação e para avaliação de qualquer política consistente” (Severino, 2006, p. 53). Além disso, podemos depreender que há um alinhamento com as demais políticas nacionais atuais para a educação que estão prevendo um tempo maior para sua implementação, tal como o Plano de Desenvolvimento da Educação (PDE).

O V PNPG também advoga que a pós-graduação tem a tarefa de produzir profissionais qualificados para atuar em diferentes espaços sociais, contribuindo para a modernização do país. Ao reconhecer que a pósgraduação é a etapa da educação mais bem-sucedida no conjunto do sistema educacional brasileiro, destaca que essa condição é fruto de políticas indutivas desenvolvidas nos últimos anos com o apoio da sociedade acadêmica brasileira. Em consequência, apresenta como um dos seus objetivos fundamentais "uma expansão do sistema de pós-graduação que leve ao expressivo aumento do número de pós-graduandos requeridos para a qualificação do sistema superior do país, do sistema de ciência e tecnologia e do setor empresarial” (Brasil, 2004, p. 9).

O documento em análise apresenta um diagnóstico da situação atual da pós-graduação no Brasil e apresenta dados estatísticos que comprovam crescimento expressivo ao longo dos anos. Apesar dos avanços quantitativos, continua registrando, tal como nos planos anteriores, que um dos principais problemas ainda persiste: a distribuição desigual do sistema em termos de distribuição dos cursos entre as regiões.
Além dessa questão, já apontada em análises anteriores, o V PNPG destaca a necessidade de redefinir os recursos e a organização orçamentária para a pós-graduação e do modelo organizacional vigente. A análise do modelo organizacional é feita tendo por parâmetro o sucesso da pós-graduação que se traduz em números e estatísticas frutos do rígido processo de avaliação criado pela Coordenação de Aperfeiçoamento de Pessoal de Nível Superior (CAPES) e realizado por pares. Em tal quadro, propostas de mudanças são geralmente consideradas com restrições, ao se levar em conta o binômio modelo/avaliação. Mesmo assim, as demandas diferenciadas que emergem de cada região/estado/programa, que não têm encontrado apoio suficiente para serem levadas adiante em função do modelo atual, acarretam desafios para o setor como os listados no documento em tela:

\footnotetext{
Flexibilização do modelo de pós-graduação, a fim de permitir o crescimento do sistema; [...] Atuação em rede, para diminuir os desequilíbrios regionais na oferta e desempenho da pós-graduação e atender às novas áreas de conhecimento. (Brasil, 2004, p. 44)
}

Mesmo que venha sendo uma questão presente no conjunto de documentos que, historicamente, têm configurado o planejamento para a pós-graduação brasileira, pode-se dizer que as assimetrias regionais são um dos pontos de destaque do V PNPG. Como pudemos identificar no Quadro 1, dos atuais 3.859 cursos de pós-graduação existentes, 2.093 estão instalados na Região Sudeste, o que corresponde a uma concentração de $54,2 \%$ do total.

Nesse âmbito, o documento traz uma discussão interessante sobre as assimetrias do sistema e conclui que, mesmo que os planos anteriores tenham manifestado preocupação com essa questão, sugerindo inclusive ações direcionadas para resolver o problema, a realidade continua a mesma: o sistema continua concentrado na Região Sudeste.

Independentemente de políticas direcionadas, nos últimos anos a Região Sul vem encontrando estratégias desenvolvi- 
mentistas e consolidando seus programas, de sorte a ocupar hoje lugar de visibilidade no sistema. O Nordeste alcançou algum destaque, porém ainda apresenta assimetrias entre seus estados. No Centro-Oeste, o quadro de assimetrias é ainda mais acentuado, uma vez que a pós-graduação concentra-se em Brasília. E, no Norte, região de extrema importância nacional pela sua dimensão e diversidade, encontra-se uma pós-graduação incipiente, com concentração em dois estados de uma região de dimensão continental. (Brasil, 2004, p. 46)

De modo mais explícito, são as análises a respeito dos investimentos financeiros que desnudam as diferenças regionais, colocando desafios que não podem ser enfrentados apenas por políticas governamentais especificamente voltadas para a pós-graduação. É nesse sentido que V PNPG destaca:

[...] os dados indicam uma correlação entre as variáveis PIB, número de docentes na pós-graduação e valor nos investimentos efetuados em bolsas pelas agências de fomento, de forma que o investimento por docente da pós-graduação seja comparativamente semelhante de uma região para outra. [...] Observa-se uma maior concentração de investimentos públicos onde existe maior capacidade instalada de recursos humanos qualificados e de infraestrutura. $\mathrm{O}$ crescimento de grupos emergentes é prejudicado numa situação de orçamentos reais decrescentes e da tendência de políticas públicas de canalizar parte significativa dos investimentos nos grupos mais consolidados. (Brasil, 2004, p. 47)

Caso não haja políticas de indução efetivas que busquem mudar esse quadro, pouco será feito no sentido de alcançar e consolidar o objetivo principal desse plano: "o crescimento equânime do sistema nacional de pós-graduação, com o propósito de atender com qualidade as diversas demandas da sociedade, visando ao desenvolvimento científico, tecnológico, econômico e social do país” (idem, ibidem, p. 54).

As informações apresentadas permitem afirmar que, desde os anos de 1970, tem sido definida e implementada uma contínua e perene política para a pós-graduação brasileira, como expressam os pro- gramas de ação antes comentados e o reconhecimento acadêmico-científico que tem sido imputado ao sistema, tanto no Brasil como no exterior. Não obstante, são muitos os desafios postos pelas suas assimetrias, como exemplificaram as reflexões feitas até aqui. Tais reflexões contribuem para que tenhamos uma visão do perfil e do padrão que a pós-graduação assume no presente, dentre elas a pós-graduação em educação, foco específico de nosso interesse e da qual trataremos a seguir.

\section{A pós-graduação em educação, a pesquisa e o tratamento do tema política educacional}

Segundo dados fornecidos pela CAPES, ${ }^{2}$ no primeiro semestre de 2008 o Brasil contava com 89 programas de pós-graduação em educação, divididos entre os que têm apenas cursos de mestrado (49) e os que têm cursos de mestrado e doutorado (39), além de um apenas com curso de doutorado. Esses programas abarcavam 88 mestrados e 40 doutorados, totalizando 128 cursos. Desse total, 11 programas estão localizados na Região Nordeste, sendo 6 com cursos de mestrado e 5 com cursos de mestrado e doutorado, todos eles funcionando em universidades públicas.

Como observamos, na área da educação as assimetrias regionais também se manifestam. Em relação à última avaliação trienal da CAPES, realizada em 2007 pra o período 2004 a 2006, foram aprovados 89 programas no Brasil cujas notas variam entre 6 e 3. Desse total, 75 estão concentrados no Sul e no Sudeste, enquanto nas regiões Norte e Nordeste se encontram apenas 14 programas, sendo que, desse total, 11 estão especificamente no Nordeste.

Em contrapartida, é possível dizer que, mesmo de maneira esparsa e incipiente, a pesquisa sobre educação no Brasil vem sendo desenvolvida desde o início do século passado. A criação do Instituto Nacional

${ }^{2}$ Fonte: CAPES/MEC. Programas reconhecidos, atualizado em 15 de abril de 2008, visitado em 8 de maio de 2008 (www. capes.gov.br). 
de Estudos e Pesquisas Educacionais Anísio Teixeira (INEP), no final da década de 1930, foi decisiva para a emergência de estudos sistemáticos nessa área. Nos anos de 1950, com a criação do Centro Brasileiro de Pesquisas Educacionais os Centros de Pesquisa Regionais se espalharam por várias regiões do país, e "a construção do pensamento educacional brasileiro, mediante pesquisa sistemática, encontrou espaço específico de produção, formação e estímulo" (Gatti, 2001, p. 65).

No entanto, foi com a implementação da pósgraduação que se acelerou o desenvolvimento da área de pesquisa em educação, tanto que é possível afirmar que é no âmbito da pós-graduação que efetivamente essa prática acontece (André, 2001). Sanchez Gamboa (2003) chega a comentar que a produção científica concernente se restringe basicamente ao que é feito no interior desse componente do ensino superior brasileiro, o que levou ao desenvolvimento e à manutenção do binômio pós-graduação/pesquisa.

No que diz respeito à relação entre graduação e pós-graduação, pode-se afirmar que esta última ocupa papel importante na organização da educação superior, já que é exigido que o corpo docente de uma instituição de ensino superior tenha um mínimo de professores titulados em seus quadros, principalmente com o título de mestre ou de doutor. Cury (2004) diz que a concentração da pesquisa na pós-graduação leva à existência de uma “dupla rede” no ensino superior: na graduação, a docência; na pós-graduação, a pesquisa, fragmentando e hierarquizando as atividades acadêmicas.

O surgimento da pós-graduação em educação data da década de 1960, quando foi criado o mestrado em educação da Pontifícia Universidade Católica do Rio de Janeiro (PUC-Rio), no ano de 1966. Sua expansão ocorreu, de fato, nos anos de 1970, quando o governo instituiu o Sistema Nacional de Pós-Graduação; a efetiva produção de teses e dissertações se iniciou apenas em 1973.

Como já comentado, essa área também se desenvolveu no contexto do projeto da modernização conservadora do regime militar. Como não poderia deixar de ser, a pesquisa educacional sofreu influências da filosofia de ação então vigente, que, entre outras coisas, defendia o fortalecimento das relações entre educação, desenvolvimento econômico, necessidades do mercado e segurança nacional (Germano, 2005).

A pouca tradição de pesquisa da área influenciou a organização inicial dos cursos. Nesse sentido, principiaram por se estruturar em áreas de concentração com base no currículo do curso de pedagogia, daí o surgimento de áreas como filosofia e história da educação, psicologia da educação, didática e metodologia do ensino, dentre outras. Esse formato, ao delimitar uma perspectiva altamente fragmentada das subáreas de investigação, favorecia uma abordagem parcial dos fenômenos com base em uma visão segmentada e mecânica da realidade. Tal situação veio a mudar com as transformações que ocorreram na sociedade brasileira.

À medida que os programas de pós-graduação em educação foram se ampliando, não davam mais conta da pluralidade de temas e problemas que surgiam a partir da incorporação de novos docentes/pesquisadores. Além disso, as áreas de concentração também começavam a ser revistas, porque exigiam que os alunos cursassem um amplo leque de disciplinas antes de elaborar sua pesquisa, o que estendia enormemente o tempo de titulação.

A CAPES passou a propor, a partir da década de 1990, que os programas fossem organizados em linhas de pesquisa. Assim, as disciplinas tornaram-se secundárias e o que importava era que o aluno desde o início dos cursos possuísse um projeto vinculado a uma linha. Em tese, isso significava colocar a pesquisa como o centro do desenvolvimento do curso e também supunha maior articulação e aproximação entre os pesquisadores, já que o desenvolvimento de linhas de pesquisa previa a formação de grupos que a integrassem.

Para retomar a trajetória da pós-graduação, é preciso revisitar o momento em que a organização ainda era por áreas de concentração e o contexto políticoeconômico dava o norte a essas áreas nos mestrados e aos temas das pesquisas em educação da época. 
Gonçalves (2003), em pesquisa sobre a produção acadêmica brasileira, analisa 20 artigos sobre educação publicados na década de $1970 .^{3}$ Nesse contexto, observou que a maior concentração da produção data da segunda metade desse período, “quando é iniciada uma gradativa abertura e uma diminuição da censura e do controle na mídia e na produção acadêmica, simultaneamente a um fortalecimento do movimento questionador do regime político então vigente e de sua atuação” (p. 74).

Em articulação com o I PNPG e a fim de dar continuidade às suas diretrizes, em 1975 o governo lançou o Programa de Pós-Graduação em Educação. Tratava-se de um programa especial concebido com a intenção de institucionalizar o sistema na área, consolidar cursos existentes, melhorar a qualidade do ensino, aumentar a rentabilidade e controlar a expansão (CAPES, 1975, apud Ferreira, 1999).

Foi nesse período que se passou a buscar a expansão e a consolidação dos cursos de pós-graduação em educação, num momento em que, política e economicamente, o regime militar começava a dar sinais de fragilidade e de crise do projeto instituído e em que a sociedade civil intensificava a luta por uma organização social democrática.

Pouco a pouco esses anseios iriam se fazer presentes no sistema educacional e, portanto, nos programas de pós-graduação em educação. No entanto, o documento de 1975 mostrava que as áreas de concentração predominantes nos 17 cursos de mestrado em educação em funcionamento eram: administração de sistemas educacionais, ensino, aconselhamento psicopedagógico, filosofia da educação e planejamento educacional. Desse total, 10 cursos tinham como área de concentração a administração de sistemas educacionais. De certo modo, isso pode ser tomado como reflexo da concepção tecnicista então predominante: os problemas da educação tinham, dentre suas causas principais, a má administração dos sistemas e escolas,

${ }^{3}$ Essa autora fez um estudo do tipo estado da arte, analisando 203 artigos que abordavam a relação entre Estado e educação, abrangendo o período de 1970 a 1990. decorrendo de emprego inadequado de técnicas (Freitag, 1987; Germano, 2005). O plano ressalta também a baixa produtividade dos programas, tomando como base o exame da situação da titulação dos docentes que neles atuavam e a precariedade dos seus regimes de trabalho (CAPES, 1975).

Refletindo nossas diferenças regionais, é preciso lembrar que dos 17 cursos de pós-graduação em educação existentes naquele período apenas um estava localizado no Nordeste: o mestrado em educação da Universidade Federal da Bahia (UFBA), criado em 1971. Visando corrigir essas disparidades e regular o crescimento da pós-graduação na região, o governo lançou, em 1976, o Projeto Nordeste de Pós-Graduação, que gerou frutos positivos.

O movimento de expansão regional dos cursos, entretanto, seguiria o padrão estabelecido em nível nacional, particularmente sob a regulação do Conselho Federal de Educação, ou seja, a organização dos cursos em áreas de concentração, com um elenco de disciplinas obrigatórias, eletivas e de domínio conexo, daí resultando que as escolhas das áreas de concentração ocorreram sob rígido formalismo, repetindo as denominações já existentes ou criando similares, não só no Nordeste como também nas outras regiões.

Na década de 1980, no entanto, começaram a ocorrer mudanças. Nesse sentido, houve um repensar crítico dos programas, fato evidenciado no documento elaborado pela Comissão de Avaliação da CAPES relativo ao período 1985/1986. Esse documento destacava a busca, dentro dos cursos, por disciplinas mais coerentes com suas áreas de concentração/linhas de pesquisa e por um movimento de alteração de sua estrutura curricular (Ferreira, 1999).

Nesse período, a preocupação com as desigualdades e suas repercussões na escolaridade das camadas populares e o ressurgimento dos movimentos sociais influenciaram as pesquisas em educação e fortaleceram abordagens críticas com caráter de denúncia e explicações globalizantes para os problemas existentes. Em contrapartida, a entrada de intelectuais nos postos de decisão nas estruturas governamentais levou ao "ressurgimento de estudos de caráter psicopedagógico, 
principalmente em temas como formação do professor, alfabetização e ensino de disciplinas específicas na escola elementar e secundária” (Campos \& Fávero, 1994, p. 13).

Cabe lembrar que esse período foi marcado por intensa expansão do ensino superior e da pós-graduação, que exigiu a expansão da formação de quadros no exterior a fim de atuar nessa área. O retorno desses pesquisadores para o Brasil trouxe para as universidades e para a pós-graduação contribuições que começaram a produzir diversificações nos trabalhos, tanto em relação às temáticas quanto às formas de abordagem. Também se desenvolveram e consolidaram diversos grupos de pesquisa em uma diversidade de áreas temáticas, como em alfabetização e linguagem, aprendizagem escolar, educação infantil e educação de jovens e adultos, entre outras (Gatti, 2001).

A década de 1990 e o início do século XXI nos mostram que, acompanhando o movimento da redemocratização brasileira e as mudanças ocorridas no campo educacional, os programas de pós-graduação em educação, ao se defrontarem com novas demandas, redefiniram seus modelos muito em função da problemática da sociedade brasileira.

Essa redefinição passa, por exemplo, por uma análise das demandas por pesquisa realizadas em eventos como o seminário "Pós-Graduação: enfrentando novos desafios", ${ }^{4}$ que recomendou a ampliação das fronteiras temáticas de formação, identificando cinco temas: avaliação institucional e de sistemas, educação ambiental, educação especial, educação a distância, informática e educação e a área de métodos quantitativos em educação.

$\mathrm{O}$ atendimento a essas demandas pode ser evidenciado no surgimento de novas linhas ou grupos de pesquisa dentro dos programas de pós-graduação. É importante ressaltar que a elaboração do V PNPG tomou o documento citado como um dos que embasa-

${ }^{4}$ Seminário realizado pela CAPES em 2001, concebido como uma atividade estratégica a partir da qual ela desejou dar continuidade à reflexão sobre a necessidade de repensar o desenvolvimento da pós-graduação nacional (INFOCAPES, 2001). ram suas delimitações, o que indica certa concordância com diagnósticos e indicações para cada área do conhecimento ali analisada e apresentada. O referido plano chama de inovação a inclinação sobre o discurso das políticas públicas que as pesquisas em educação se têm dedicado a fazer, mesmo que faça uma crítica ao uso inadequado da análise quantitativa dos dados subjacentes a essas políticas.

No seio desse debate, fortalecem-se e ampliamse os estudos sobre a política educacional, tema que abordaremos em seguida.

\section{A política educacional como tema de pesquisa}

A preocupação com a temática política educacional, de acordo com o enfoque teórico pelo qual é abordada, pode alimentar positivamente um processo dialético, quando se procura articular a percepção da realidade social a partir do estudo científico dos problemas envolvidos na questão educacional e as políticas públicas concernentes, entendidas como a ação do Estado.

Esse movimento expressa-se na condução das pesquisas em educação em grande parte dos programas de pós-graduação em educação, de forma que, a partir da abertura política ocorrida no Brasil em meados da década de 1980, estudos críticos sobre a condução das políticas educacionais se fazem presentes no cenário nacional. Chamamos de críticos os estudos que, ao analisar políticas implementadas, denunciam irregularidades, inconsistências/inconsequências administrativas e incoerências teórico-práticas acerca de processos implementados, entre outras perspectivas analíticas nesse sentido. E ainda aqueles que se preocupam em apontar alternativas viáveis para a implantação de uma educação com qualidade social.

Por certo esse movimento não surgiu do nada: a própria instituição da pós-graduação, durante o regime militar, plantou as sementes de uma análise mais rigorosa da política educacional brasileira. Cunha (1991, p. 59) afirma que, no início da instituição da pós-graduação no nosso país, “a política educacional era a própria matéria de trabalho dos professores, entre 
os quais se encontravam críticos do governo militar”. Naquele período houve maior aplicação de recursos, que permitiram a expansão da universidade e o desenvolvimento da produção cultural e da pesquisa científica e tecnológica, especialmente na pós-graduação, o que propiciou, contraditoriamente, condições para que dela saíssem diagnósticos, propostas e críticas consistentes sobre a educação brasileira. Tais críticas foram de alguma forma incorporadas pelos partidos políticos e outras organizações que faziam oposição ao regime militar, mas também podemos dizer que, de certa for- ma, iniciaram a tendência aos estudos sistemáticos e críticos sobre a política educacional brasileira.

Os estudos do tipo estado da arte servem de indicativo e de mapeamento dessa tendência que se firmou no campo da pós-graduação em educação. Outro indicativo é o surgimento e a consolidação de núcleos/linhas de pesquisa dentro dos programas de pós-graduação em educação cuja preocupação central diz respeito à política educacional, ao planejamento e à gestão da educação, como pode ser visto no Quadro 2, que apresenta essa realidade no Nordeste brasileiro.

Quadro 2: Linhas de pesquisa relacionadas com o tema política educacional, planejamento e gestão da educação dos programas de pós-graduação em educação do Nordeste, por universidade a que pertencem, ano de início da linha e quantidade de projetos em andamento em 2006

\begin{tabular}{|l|l|c|c|}
\hline \multicolumn{1}{|c|}{ Linha de pesquisa } & \multicolumn{1}{|c|}{ Instituição } & $\begin{array}{c}\text { Ano de } \\
\text { início }\end{array}$ & $\begin{array}{c}\text { Projetos de } \\
\text { pesquisa }\end{array}$ \\
\hline $\begin{array}{l}\text { Educação, gestão e desenvolvimento local } \\
\text { sustentável }\end{array}$ & Universidade Estadual da Bahia & 1997 & 10 \\
\hline Políticas e gestão educacional & Universidade Federal da Bahia & 1996 & 10 \\
\hline História, sociedade e educação & Fundação Universidade Federal de Sergipe & 2000 & 15 \\
\hline História e política da educação & Universidade Federal de Alagoas & 2001 & 15 \\
\hline $\begin{array}{l}\text { Política educacional, planejamento e gestão } \\
\text { da educação }\end{array}$ & Universidade Federal de Pernambuco & 1996 & 08 \\
\hline Políticas públicas e práticas educativas & Universidade Federal da Paraíba & 1997 & 13 \\
\hline Política e práxis da educação & Universidade Federal do Rio Grande do Norte & 1996 & 05 \\
\hline História, memória e política educacional & Universidade Federal do Ceará & 1993 & 06 \\
\hline $\begin{array}{l}\text { Política educacional, formação e cultura } \\
\text { docente }\end{array}$ & Fundação Universidade Estadual do Ceará & 2003 & 08 \\
\hline $\begin{array}{l}\text { Educação, movimentos sociais e políticas } \\
\text { públicas }\end{array}$ & Fundação Universidade Federal do Piauí & 1998 & 07 \\
\hline Estado e gestão educacional & Universidade Federal do Maranhão & 1995 & 07 \\
\hline
\end{tabular}

Fonte: MEC/CAPES.

Como podemos observar, todos os programas listados possuem linhas de pesquisa cuja temática se relaciona com política, gestão e planejamento da educação, cujo início data do final do século passado e início deste, que, como sabemos, está marcado por um amplo movimento de redefinição da política educacional no Brasil.

Outro destaque que podemos fazer em relação às pesquisas em foco é o surgimento e a consolidação de grupos de trabalho em instituições científicas e de pesquisas que se preocupam em estudar a problemática da política educacional. Tais instituições - a exemplo da Associação Nacional de Política e Administração da Educação (ANPAE), da Associação Nacional de Pós-Graduação e Pesquisa em Educação (ANPEd), ${ }^{5}$

${ }^{5}$ A ANPEd é uma das instituições mais importantes do Brasil para a pós-graduação em educação. Isso porque, em seus 30 anos de existência, acompanhou e acompanha o desenvolvimento desse nível da educação brasileira, participando ativamente do seu desenvolvimento e se tornando um grande veículo de divulgação, discussão e debate de grandes temas e produções que são ali desenvolvidas (Zákia \& Bianchetti, 2007; Cury, 2008). É importante destacar que a ANPEd teve e ainda tem papel importante na integração e intercâmbio de pesquisadores e na disseminação da pesquisa educacional. Contando com mais de 20 grupos de trabalho, 
do Colégio Brasileiro de Ciências do Esporte (CBCE), ${ }^{6}$ entre outras - congregam pesquisadores em nível nacional que reafirmam seu compromisso com a causa da construção histórica de uma educação pública gratuita, universal e de qualidade para todos, pelos eventos e pelas publicações que, periodicamente, tais instituições promovem.

Anteriormente chamamos a atenção para a importância dos estudos do tipo estado da arte para a evolução e análise da pesquisa educacional; neste artigo eles nos ajudarão a delimitar os estudos sobre política educacional. No âmbito da pesquisa sobre política educacional, esse tipo de estudo também se faz presente e se constitui em indício revelador da relevância que o tema vem ganhando no campo científico. Podemos citar os estudos de Azevedo e Aguiar (2001a), que se propuseram a realizar uma "reflexão sobre as características e tendências das investigações vinculados ao campo da produção intelectual dos saberes sobre a política educacional no Brasil” (p. 50-51), e os de Wittmann e Gracindo (2001), que visaram "contribuir para o avanço do conhecimento na área da administração da educação e consolidar sua base nacional de articulação e intercâmbio sistemático entre pesquisadores na área” (p. 11).

Como mencionado, num estudo sobre a relação entre Estado e educação como tema tratado na produção acadêmica brasileira, Gonçalves (2003) tem como corpus da sua pesquisa periódicos de diversas áreas de

que se concentram em temas específicos dos estudos de questões educacionais, a ANPEd sinaliza bem a expansão da pesquisa educacional nas instituições de ensino superior ou centros independentes, públicos ou privados. Isso pode ser constatado por suas reuniões anuais, que têm congregado em torno de dois mil pesquisadores, com aumento sistemático de trabalhos submetidos à apreciação das comissões científicas do evento (Gatti, 2001).

${ }^{6}$ O CBCE é uma instituição científica que se ocupa da produção do conhecimento na área de educação física e ciências do esporte. Os debates são organizados no seio de 12 grupos de trabalho temático; dentre eles o GTT 10 - Políticas Públicas, que aborda as questões relativas às políticas para educação física, esporte e lazer. conhecimento, entre elas a educação, que constituem $78,2 \%$ dos 202 artigos selecionados para a pesquisa, totalizando 158 trabalhos. Interessa-nos destacar aqui a relação entre os temas abordados e os períodos estudados, o que nos permite indicar tendências da pesquisa em política educacional nesses períodos. ${ }^{7}$ Nesse sentido, os dados que a autora apresenta a partir da década de 1980 são representativos desse cenário de mudança e de abertura política aludido anteriormente, que exerceu e exerce influências sobre a produção do conhecimento em política educacional.

A pesquisa aponta que os temas dos artigos da década de 1980 estavam relacionados à capacidade administrativa e aos mecanismos desenvolvidos para garantir ao Estado maior eficiência e racionalização. Os artigos colocam em foco a ineficiência e omissão do Estado com a educação; há poucas propostas de concretização e efetivação das demandas surgidas. Os textos voltam-se também para a discussão da legislação, visto que estava em tramitação a Constituição de 1988 e algumas discussões remetiam à formulação da nova Lei de Diretrizes e Bases da Educação Nacional (LDBEN). "Daí a grande ênfase temática em implementação de políticas educacionais e gestão de sistemas educacionais, enfocando em especial aspectos administrativos da atuação do Estado na educação" (Gonçalves, 2003, p. 105).

A década de 1990, no campo político, foi marcada pela busca da estabilidade econômica no Brasil e pelos processos de reforma do Estado, que tiveram seus reflexos na educação. A elaboração do Plano Decenal de Educação (1993-2003), a promulgação da nova LDBEN (lei n. 9.394 de dezembro de 1996), entre outras medidas de política, influenciam sobremaneira a produção do conhecimento em política educacional. Além disso, o panorama político, marcado pela assunção do modelo neoliberal, pela reforma do Estado e seus impactos no setor, marcou a produção acadêmica concernente.

${ }^{7}$ A autora delimitou três períodos para análise: décadas de 1970, 1980 e 1990. 
Na década de 1990 pode-se notar como a produção acadêmica da primeira metade do período volta-se para as discussões e expectativas de que demandas da Educação sejam contempladas na LDB, fortalecendo garantias já presentes na Constituição de 1988 e especificando melhor como efetivá-las. [...] O perfil estatal neoliberal é o foco principal dos autores, além de outros itens que a ele são relacionados. Por exemplo, a ineficiência e omissão, agora discutidos sob o entendimento de desresponsabilização; autoritarismo e centralização, simultaneamente à tendência de descentralização, implicando concentração de poder por meio de avaliação e controle da distribuição de responsabilidades. (Gonçalves, 2003, p. 151-152)

As pesquisas de Azevedo e Aguiar (2001a, 2001b) revelam que os estudos sobre a temática política educacional se vêm ampliando a cada ano. Os dados apontam, por exemplo, para uma gama de estudos sobre políticas e programas governamentais, englobando investigações sobre definições gerais da política educacional da União, de estados e municípios. Abordam também programas e projetos específicos de cada uma das esferas administrativas, que constituem o universo de maior expressão quantitativa das duas pesquisas em foco.

\footnotetext{
A tônica das investigações agrupadas na categoria "Estudos sobre Programas e Políticas de Governo” é, sobretudo, a focalização de novas experiências na condução da política educacional ou na implementação de programas e projetos em estados federados ou em seus municípios. (Azevedo \& Aguiar, 2001a, p. 62)

Por último se tem o bloco temático que agrega os trabalhos voltados para a avaliação de programas e projetos, o maior do grupo, englobando 73\% do total analisado. (Azevedo \& Aguiar, 2001b, p. 75)
}

Considerando que os trabalhos que foram objeto de estudo das pesquisas aludidas advêm sobretudo das práticas sociais que configuram a produção do conhecimento nos programas de pós-graduação em educação e os dados quantitativos que indicam maior expressividade das investigações sobre programas e projetos educacionais é que se pode dizer que essa é uma temática que possui legitimação do campo científico da pós-graduação em educação.

Aqui retomamos os construtos de Bourdieu (2003), que diz que a legitimação se processa por meio de uma série de ritos e práticas que passam pela percepção da importância e interesse por aquilo que se pesquisa, não apenas para o pesquisador mas também para “os outros”. Esses “outros” são entendidos como os pares-concorrentes da comunidade científica, o que leva a luta pela autoridade nesse campo incidir sobre as escolhas (político-científicas) que o pesquisador faz do seu objeto, o que reforça a inexistência da tese que advoga a neutralidade dos processos investigativos.

Nesse contexto, como sabemos, ao mesmo tempo que a Educação tem ganhado uma especial centralidade - por a ciência estar sendo progressivamente convertida em força produtiva - assiste-se, local e mundialmente, às sucessivas ações do Estado no sentido de reformulação dos sistemas de ensino. Essas ações, por sua vez, têm se caracterizado pela agilidade de sua decisão e implementação, distanciando ainda mais o fosso que separa o tempo da produção dos saberes advindos das investigações, do tempo político das decisões sobre a política educacional. Fato que é agravado pelos parâmetros que estão regendo tais decisões, já que tendem a distanciar a política educacional do atendimento dos direitos de cidadania, colocando-a na direção do aumento dos níveis de exploração e de exclusão que caracterizam a atual fase do desenvolvimento. (Azevedo \& Aguiar, 2001a, p. 51-52)

Não podemos deixar de destacar que as problemáticas que envolvem o financiamento das pesquisas ainda é um entrave para a sua consolidação. Como se sabe, a pesquisa universitária é financiada sobretudo por recursos externos à instituição, o que traz consequências. Figueiredo e Sobral (1999) destacam o problema da irregularidade das verbas, a interferência na escolha dos temas de pesquisa (o que reduz a autonomia do pesquisador), a seletividade das pesquisas (algumas áreas são consideradas arbitrariamente prioritárias) e a burocratização para liberação dos recursos. Acrescentamos a esses a redução paulatina 
das verbas e o refinamento dos critérios para seleção dos pesquisadores e suas pesquisas, que, nesses tempos de competitividade, tornam a busca de financiamento uma verdadeira via crucis para os iniciantes.

\section{À guisa de conclusão}

Os dados apresentados e as discussões que travamos até aqui permitem afirmar que a pós-graduação se vem constituindo em espaço promissor para a pesquisa no campo da educação, tanto no Brasil como na Região Nordeste. Permitem afirmar também que a temática "política educacional” ganhou status significativo nessas investigações, conforme argumentos antes apresentados.

Mas um ponto importante a considerar diz respeito ao impacto social que os estudos sobre a política educacional podem ou poderiam ter. De forma geral, arriscamo-nos a dizer que nem sempre tal impacto é uma preocupação do pesquisador ou da instituição a que ele se vincula, já que a vida acadêmica muitas vezes se distancia da vida prática. São recorrentes os comentários a respeito da enorme quantidade de teses, dissertações e demais relatórios de pesquisa que “dormem nas prateleiras empoeiradas das bibliotecas universitárias”, ainda que a divulgação eletrônica tenha possibilitado um acesso público a essa produção bem maior do que havia em décadas passadas.

Não obstante, a questão que se coloca é o aproveitamento que os poderes públicos, particularmente os encarregados das políticas de educação, fazem das análises e sugestões presentes nas referidas pesquisas, de modo que sejam incorporados subsídios daí decorrentes quando da busca de soluções durante os processos decisórios para a gama de problemas encontrados em nossos processos educacionais.

Vale advertir ao leitor que não estamos ignorando as distâncias que podem separar os projetos de governo em cada conjuntura - e, por conseguinte, os referenciais e as respectivas prioridades na definição e implementação de programas e projetos - e os referenciais teóricos e metodológicos que norteiam as investigações dos pesquisadores sobre eles. Além disso, existe quase sempre um descompasso entre o tempo político (dos governantes e gestores à frente da máquina governamental) e o tempo de desenvolvimento e maturação de uma pesquisa. Os primeiros têm urgência na elaboração e nas concretizações de ações políticas; em decorrência, preferem encomendar estudos a pesquisadores com quem têm afinidades e sobre tema específico com tempo de realização bastante delimitado. Dessa forma, pouco procuram saber do conhecimento produzido ou em produção nas universidades.

Gatti (1986, 1994), analisando essa problemática, conclui que há insuficiente participação das instituições de ensino superior nos projetos de desenvolvimento ou nas inovações do sistema educacional, bem como pouca utilização das pesquisas educacionais. E aponta como fatores preponderantes para esse quadro os seguintes:

\section{[...] desvinculação das universidades em relação aos pro- blemas práticos; visão idealizada e teórica da universidade sobre o ensino; falta de contato dos órgãos governamentais com a universidade; caráter teórico das pesquisas; inexistên- cia quase total de trabalhos conjuntos; falta de divulgação dos resultados das pesquisas; dificuldades dos administra- dores de ensino de fazer a passagem da teoria para a prática; rigidez do sistema educacional na absorção de propostas inovadoras; a pouca importância atribuída à pesquisa em alguns segmentos governamentais. (Gatti, 2001, p. 113)}

Nessa mesma linha, Gohn (2005) indica que as investigações desenvolvidas nas universidades têm de retornar às escolas com propostas de soluções ou análises mais detalhadas sobre os objetos que são foco de investigação: "Só assim as pesquisas poderão ser ferramentas que promovam alterações qualitativas, que contribuam para a melhoria das escolas e das relações que lá se desenvolvem” (p. 271). É preciso considerar, entretanto, que, no caso dos estudos sobre o tema política educacional, esse caminho de retorno à escola, além de passar pelas iniciativas dos pesquisadores ou de suas instituições, passa necessariamente pelos gestores e pelas prioridades governamentais em 
cada conjuntura, como também pelos distintos tipos de articulação entre as três esferas de governo.

Duas outras questões também se colocam. De um lado, nem sempre os pesquisadores gostariam de ter seus estudos diretamente atrelados à máquina governamental, o que poderia cercear a autonomia de que devem se revestir as práticas universitárias e acadêmicas. No entanto, materializadas em projetos e programas educacionais, as ações políticas estão sendo constantemente submetidas à análise dos pesquisadores. De outro, as investigações na área da política educacional, de resto como nas demais áreas das políticas públicas, certamente acabam por evidenciar com maior nitidez o movimento que articula de modo muito próximo lutas políticas (politics) e análise dos programas de ação (policy). Tal situação pode conduzir, com muita facilidade, a que a análise se torne secundária em relação à luta política, fragilizando ambas.

Nesse sentido, não podemos perder de perspectiva que, como sugere Bourdieu (2003), o campo da pesquisa em política educacional, assim como outros campos científicos, está marcado por escolhas, ordenações, seleções e demais atos que configuram a existência e as formas de organização de um campo e, direta ou indiretamente, trazem as marcas das relações de força e de poder próprias desse espaço. É também fortemente influenciado pelas especificidades conferidas pela sua própria área temática: os condicionantes advindos da política educacional e, portanto, da ação do Estado (Azevedo, 1997). É essa ação, materializada em programas e projetos educacionais, "que se encarrega, em última instância, de fazer emergir múltiplos objetos em que se transmuda a sua temática e dos quais vão se ocupar os pesquisadores que convergem para esse campo de pesquisa” (Azevedo \& Aguiar, 2001a, p. 50).

Quando perguntamos sobre a produção do conhecimento em política educacional e a legitimação desse campo acadêmico, observamos que é necessário investigar os limites existentes e os avanços conquistados no que concerne às relações de poder que se estabelecem dentro de uma área acadêmica, de forma que imprima para esses novas significações em articulação com a complexidade do real. São questões que decorrem das problematizações feitas antes e que requerem tratamento específico, o que foge aos objetivos e aos limites do presente artigo, mas que pretendemos aprofundar em estudo futuro.

\section{Referências bibliográficas}

ANDRÉ, Marli. Pesquisa em educação: buscando rigor e qualidade. Cadernos de Pesquisa, n. 113, p. 51-64, jul. 2001.

AZEVEDO, Janete M. Lins. A educação como política pública. Campinas: Autores Associados, 1997.

. As humanidades no contexto da pós-graduação brasileira. Recife: s.ed., 2004. (Texto inédito.)

;; AGUIAR, Márcia Ângela. Características e tendên-

cias dos estudos sobre a política educacional no Brasil: um olhar a partir da ANPEd. Educação \& Sociedade, Campinas, v. 22, n. 77, p. 49-70, dez. 2001a.

Políticas de educação: concepções e programas. In: WITTMANN, Lauro Carlos; GRACINDO, Regina Vinhaes (Coords.). $O$ estado da arte em política e gestão da educação no Brasil: 1991 a 1997. Brasília: ANPAE; Campinas: Autores Associados, 2001b. p. 71-87. BOURDIEU, Pierre. O campo científico. In: ORTIZ, Renato (Org.). A sociologia de Pierre Bourdieu. São Paulo: Olho D’água, 2003. p. $112-143$.

CAMPOS, Maria Malta; FÁVERO, Osmar. A pesquisa em educação no Brasil. Cadernos de Pesquisa, São Paulo, n. 88, p. 5-17, fev. 1994.

CUNHA, Luiz Antônio. Educação, Estado e democracia no Brasil. São Paulo: Cortez; Niterói: EdUFF; Brasília: FLACSO do Brasil, 1991.

CURY, Carlos Roberto Jamil. Graduação/pós-graduação: a busca de uma relação virtuosa. Educação e Sociedade, Campinas, v. 25, n. 88, p. 777-793, out. 2004.

. Quadragésimo ano do parecer CFE n. 977/65. Revista Brasileira de Educação, n. 30, p. 7-20, número especial, set./dez. 2005. . Trinta por trinta: dimensões da pós-graduação em educação. Revista Brasileira de Educação, v. 13, n. 37, p. 162-167, jan./abr. 2008.

FERREIRA, Rosilda Arruda. A pesquisa cientifica nas ciências sociais: caracterização e procedimentos. Recife: Ed. Universitária da UFPE, 1999. 
A pós-graduação no Brasil, a pesquisa em educação e os estudos sobre a política educacional

FIGUEIREDO, Vilma; SOBRAL, Fernanda A. de F. A pesquisa nas universidades brasileiras. In: VELLOSO, Jacques (Org.). Universidade pública: política, desempenho, perspectivas. Campinas: Papirus, 1999.

FREITAG, Bárbara R. Escola, estado e sociedade. 6. ed. São Paulo: Cortez, 1987.

GATTI, Bernardete A. Participação do pessoal da educação superior nas reformas e inovações do sistema educacional. Cadernos de Pesquisa, n. 59, p. 3.014, nov. 1986.

. Pesquisa educacional, ações e políticas educacionais. Boletim: textos para discussão, Brasília: INEP, p. 1-7, 1994.

. Implicações e perspectivas da pesquisa educacional

no Brasil contemporâneo. Cadernos de Pesquisa, n. 113, p. 65-81, jul. 2001.

GERMANO, José Wellington. Estado militar e educação no Brasil: 1964-1985 (um estudo sobre a política educacional). 4. ed. São Paulo: UNICAMP/Cortez, 2005.

GOHN, Maria da Glória Marcondes. A pesquisa na produção do conhecimento: questões metodológicas. ECCOS - Revista Cientifica, v. 7, n. 2, p. 253-274, jul./dez. 2005.

GONÇALVES, Nádia Gaiofatto. A relação Estado e educação na produção acadêmica brasileira (1971-2000). Tese (Doutorado em Educação) - Faculdade de Educação, Universidade de São Paulo, São Paulo, 2003.

INFOCAPES. Boletim Informativo da CAPES, Brasília: CAPES, v. 9, n. 2, v. 9, n. 3, 2001.

MARTINS, Ricardo A. A pós-graduação no Brasil: uma análise do período de 1970-90. Educação Brasileira, Brasília, v. 13, n. 27, p. 23-41, 1991.

O’DONNELL, Guillermo. El Estado burocrátic-autoritario. Buenos Aires: Editorial de Belgrano, 1982.

RAMALHO, Betania Leite; MADEIRA, Vicente de Paulo C. A pós-graduação em educação no Norte e Nordeste: desafios, avanços e perspectivas. Revista Brasileira de Educação, n. 30, p. 70-81, número especial, set./dez. 2005.

SANCHEZ GAMBOA, Silvio. As condições da produção científica em educação: do modelo de áreas de concentração aos desafios das linhas de pesquisa. Educação temática digital, v. 4, n. 2, p. 78-93, jan. 2003.

SEVERINO, Antonio Joaquim. A avaliação no PNPG 2005-2010 e a política de pós-graduação no Brasil. In: FERREIRA, Naura Syria Carapeto (Org.). Políticas públicas e gestão da educação: polêmicas, fundamentos e análises. Brasília: Líber Livro, 2006. p. 51-74.
VELLOSO, Jacques. Introdução. In: VELLOSO, Jacques (Org.). A pós-graduação no Brasil: formação e trabalho de mestres e doutores no país. Brasília: CAPES/UNESCO, 2002.

WITTMANN, Lauro Carlos; GRACINDO, Regina Vinhaes (Coords.). $O$ estado da arte em política e gestão da educação no Brasil: 1991 a 1997. Brasília: ANPAE; Campinas: Autores Associados, 2001.

ZÁKIA, Sandra; BIANCHETTI, Lucídio. Pós-graduação e pesquisa em educação no Brasil: o protagonismo da ANPEd. Revista Brasileira de Educação, v. 12, n. 36, set./dez. 2007.

\section{Documentos}

BRASIL. Parecer $n^{\circ}$ 977/65. Aprovado em 3 de dezembro de 1965. Brasília: MEC/CEF, 1965. Disponível em: <http://www.capes.gov. br/capes>. Acesso em: 21 mar. 2005.

BRASIL. I Plano Nacional de Pós-Graduação. Brasília: MEC/ CAPES, 1975. Disponível em: <http://www.capes.gov.br/capes>. Acesso em: 21 mar. 2005.

BRASIL. II Plano Nacional de Pós-Graduação. Brasília: MEC/ CAPES, 1982. Disponível em: <http://www.capes.gov.br/capes>. Acesso em: 21 mar. 2005.

BRASIL. III Plano Nacional de Pós-Graduação. Brasília: MEC/ CAPES, 1986. Disponível em: <http://www.capes.gov.br/capes>. Acesso em: 21 mar. 2005.

BRASIL. Plano Nacional de Pós-Graduação 2005-2010. Brasília: MEC/CAPES, 2004. Disponível em: <http://www.capes.gov.br/ capes>. Acesso em: 21 mar. 2005.

ANA LÚCIA FELIX DOS SANTOS, doutora em educação pelo Programa de Pós-Graduação em Educação da Universidade Federal de Pernambuco (UFPE), é professora do Centro Acadêmico do Agreste dessa universidade e pesquisadora do Núcleo de Estudos e Pesquisas em Política Educacional, Planejamento e Gestão do Programa de Pós-Graduação em Educação da mesma instituição. Publicações recentes: em coautoria com GOMES, Alfredo Macedo Gomes; MELO, Darci Lira. Escola de gestores: política de formação em gestão escolar (Revista Brasileira de Política e Administração da Educação, v. 25, n. 2, p. 263-281, maio/ago. 2009); Política educacional no Município de Camaragibe: o caso da educação física (In: MENEZES, Vilde Gomes (Org.). Gestão democrática, participação popular e políticas públicas: a experiência de Camaragibe (Recife: Edições Bagaço, 2005. p. 361-398). 
Pesquisa atual: "Políticas de educação, municípios e o regime de colaboração da União”.E-mail: analufelix@gmail.com

JANETE MARIA LINS DE AZEVEDO, doutora em ciências sociais pela Universidade Estadual de Campinas (UNICAMP), com estágio de pós-doutoramento em educação na Université Paris 8, é professora do Programa de Pós-Graduação em Educação da Universidade Federal de Pernambuco (UFPE). Publicações recentes: Programas federais para a gestão da educação básica: continuidade e mudanças (Revista Brasileira de Política e Administração da
Educação, v. 25, n. 2, p. 211-231, maio/ago. 2009); em coautoria com GOMES, Alfredo Macedo. Intervenção e regulação: contribuições ao debate no campo da educação (Linhas Críticas, v. 15, n. 28, p. 95-107, jan./jun. 2009); A educação e a cidade (Presença Pedagógica, v. 15, n. 87, p.77-80, maio/jun. 2009). Pesquisa atual: "Políticas de educação, municípios e o regime de colaboração da União”.E-mail: janete.lins@gmail.com

Recebido em março de 2009 Aprovado em julho de 2009 
Key words: representations of masculinity; teaching of Physics; research activities.

\section{Representaciones de masculinidades latentes en clases de física de la escuela secundaria}

El estudio caracteriza aspectos latentes de masculinidades que traen implicaciones para el aprendizaje individual y colectivo de una clase de la escuela secundaria. Clases de física del primer año de una escuela secundaria fueron acompañadas a lo largo de un año. A microanálisis de una secuencia de seis clasesgravadas en audio y en videoenvolviendo una actividad que simula el trabajo de una comunidad científica, caracteriza las interacciones predominantes entre los jóvenes. Las masculinidades destacadas se movilizan en torno del estímulo frente a situaciones desafiantes y de competición, de la curiosidad por el fenómeno investigado, del desafío a las reglas establecidas en la conducción de la actividad. Entre las implicaciones del estudio, se destaca la necesidad de tener en cuenta las manifestaciones de masculinidades que puedan comprometer el desarrollo de las actividades en la clase y el funcionamiento de los grupos de aprendizaje.

Palabras claves: representaciones de masculinidad; enseñanza de física; actividades investigadoras.

Marisa Vorraber Costa e Mariangela Momo

\section{Sobre a "conveniência” da escola}

O artigo pretende mostrar um novo “uso” para a escola, atrelado à lógica do atual estágio da globalização, em que a cultura ocupa uma posição singularmente importante, entremeando-se na vida social, nos circuitos econômicos e regimes políticos. Recorrendo à teorização de George Yúdice sobre os usos da cultura na era global, são analisados três projetos sociais - Você Apita, Tim Música nas Escolas e Escola Aberta - considerados expressivos da forma como empresas, organizações públicas e iniciativas da sociedade civil se articulam com a cultura e a educação para fazer os mercados globalizados se movimentarem, mas não apenas em seus próprios interesses, embora esses persistam no topo das prioridades. Há indícios de que a “conveniência” da escola ultrapassa o interesse mercantil imediato e se projeta como estratégia direcionada a uma variada gama de propósitos sociopolíticos, econômicos e culturais, entre eles a possibilidade de governar a vida das pessoas, forjando visões de mundo e de sociedade.

Palavras-chave: escola e globalização; escola e cultura; governamento; projetos sociais; biopolítica.

On the "convenience" of school This article aims at showing a new "use" for school that is linked to the logic of the current stage of globalization, in which culture occupies a uniquely important position, interwoven with social life, economic circuits and political regimes. Making use of George Yúdice's theorization about the uses of culture in the global era, three social projects are analyzed - Você Apita, Tim Música nas Escolas and Escola Aberta. These projects are considered expressive of the way in which businesses, public entities and civil society initiatives are articulated with both culture and education in order to make globalized markets move, but not only favouring their own interests, although these remain as top priorities. Evidence exists that the "convenience" of school outweighs the immediate business interest and projects itself as a strategy directed towards a wide range of social-political, economic and cultural purposes. Among them is the possibility of governing people's lives, forging both world and societal views.

Key words: school and globalization; school and culture; government; social projects; bio-politics.

Sobre la "conveniencia" de la escuela El artículo pretende mostrar un nuevo “uso" para la escuela, vinculado a la lógica de la etapa actual de la globalización en la que la cultura ocupa una posición singularmente importante, entrelazándose en la vida social, en los circuitos económicos y en los regímenes políticos. Recurriendo a la teorización de George Yúdice sobre los usos de la cultura en la era global, se analizan tres proyectos sociales Você Apita, Tim Música nas Escolas y Escola Aberta - considerados expresivos de la forma como empresas, organizaciones públicas e iniciativas de la sociedad civil se articulan con la cultura y con la educación para hacer con que los mercados globalizados se muevan, pero no sólo en sus propios intereses, aunque ellos persistan en la cima de las prioridades. Hay indicios de que la "conveniencia" de la escuela sobrepasa el interés mercantil inmediato, y se proyecta como estrategia dirigida hacia una variada gama de propósitos socio-politicos, económicos y culturales. Entre ellos, la posibilidad de gobernar la vida de las personas, forjando visiones de mundo y de sociedad.

Palabras claves: escuela y globalización; escuela y cultura; gobierno; proyectos sociales; biopolítica.

Ana Lúcia Felix dos Santos e Janete Lins de Azevedo

A pós-graduação no Brasil, a pesquisa em educação e os estudos sobre a política educacional: os contornos da constituição de um campo acadêmico

Este artigo problematiza especificidades que cercam o campo acadêmico da 
educação, focalizando o modo como nele se apresenta o subcampo composto pelos estudos sobre a temática política educacional. Para tanto, parte de breve abordagem histórica sobre a constituição da pós-graduação no Brasil, com ênfase nas políticas voltadas para a pós-graduação em educação.

Considera-se que os cursos de mestrado e doutorado representam um lugar privilegiado de produção do conhecimento, dada a centralidade que neles deve assumir a pesquisa científica. Procura-se analisar a inserção e a evolução da pesquisa educacional nesse processo, o que, por seu turno, é usado como estratégia com vista a apontar o lugar dos estudos sobre o tema política educacional nos programas de pós-graduação em educação, particularmente no Nordeste.

Palavras-chave: pós-graduação e pesquisa; política educacional; Brasil; Nordeste.

\section{Postgraduate studies in Brazil,} research in education and studies on educational policy: contours of the constitution of an academic field

This article problematises specificities that surround the academic field of education, focusing on the way in which the sub-field composed of studies on educational policy is represented. To that end, it starts with a brief historical introduction to the constitution of postgraduate studies in Brazil, with emphasis on policies directed at postgraduate studies in education. Masters' and doctoral courses are considered to represent a privileged place in the production of knowledge, given the centrality which scientific research should assume in them. We seek to analyse the insertion and evolution of educational research in that process which, in its turn, is used as a strategy with a view to indicate the place of studies on educational policy in programmes of postgraduate studies in education, particularly in the northeast region of Brazil.

Key words: postgraduate studies and research; educational policy; Brazil; Northeast.

El postgrado en Brasil, la pesquisa en educación y los estudios sobre la política educacional: los contornos de la constitución de un campo académico

Este artículo trata especificamente los problemas que rodean el campo académico de la educación, focalizando el modo como en él se presenta el subcampo compuesto por los estudios sobre la temática politica educacional. Para esto, parte de un breve abordaje histórico sobre la constitución del postgrado en Brasil, con énfasis en las politicas dirigidas para el postgrado en educación. Se considera que los grupos de máster y doctorado representan un lugar privilegiado de producción del conocimiento, dado a la centralidad que en ellos debe asumir la pesquisa científica. Se procura analizar la inserción y la evolución de la pesquisa educacional en este proceso, lo que, por su turno, es usado como estrategia con vista a apuntar el lugar de los estudios sobre el tema política educacional en los programas de postgrado en educación, particularmente en Nordeste.

Palabras claves: postgrado y pesquisa; política educacional; Brasil; Nordeste.

Estrella Bohadana e Lílian do Valle

\section{O quem da EAD}

Em curto espaço de tempo, a educação a distância (EAD) passou de recurso marginal a menina dos olhos das políticas públicas e das ações empresariais. Hoje, não é possível desconsiderar o impacto que a introdução da EAD online vem causando em nossas formas correntes de conceber e de praticar a educação e a comunicação. Seus mais ardorosos defensores proclamam que as tecnologias de informação e de comunicação estão engendrando um novo tipo de sociedade e de humano. No entanto, tem-se a impressão de que o discurso de franca ruptura com o passado resulta não só da crença exacerbada nos meios tecnológicos, como da impossibilidade de responder as objeções que lhe poderiam ser feitas. Nesse sentido, torna-se agora urgente investir no aprofundamento teórico - que permitirá, talvez, entender e qualificar as rupturas que devam ser realizadas e aquelas que devam ser evitadas. É para a construção de instrumentos conceituais que favoreçam tal elucidação que o presente artigo pretende contribuir.

Palavras-chave: EAD on-line; cibercidadão; modernidade e tecnicismo; formação humana e democracia; sujeito isolado.

\section{The whom of distance education}

In a short period of time, distance education was transformed from a marginal resource to the apple of the eye of public policies and business actions. Today one cannot ignore the impact that the introduction of e-learning has caused on our current ways of conceiving and practicing education and communication. Its most ardent defenders proclaim that information and communication technologies are engendering a new type of society and human being. However, one has the impression that the discourse of evident rupture with the past results not only from an exaggerated belief in technological resources but also from the impossibility of responding to the objections that could arise. In that sense, it is now urgent to invest in further theoretical studies, which will perhaps allow us to understand and qualify the ruptures that must 